\title{
HispanismeS
}

Revue de la Société des Hispanistes Français

$18 \mid 2021$

Murs, barrières, obstacles dans les mondes hispaniques II

\section{Del muro a la pantalla, y de la pantalla a la escritura}

De las fronteras entre ficción y autoficción en la obra de Almodóvar

Du mur à l'écran et de l'écran à l'écriture : les frontières entre fiction et

autofiction dans l'œuvre d'Almodóvar

From the wall to the screen, and from the screen to writing: the boundaries

between fiction and autofiction in Almodóvar's work

\section{Belén Hernández Marzal}

\section{(2) OpenEdition}

\section{Journals}

Edición electrónica

URL: https://journals.openedition.org/hispanismes/14320

DOI: 10.4000/hispanismes. 14320

ISSN: 2270-0765

Editor

Société des Hispanistes Français

Referencia electrónica

Belén Hernández Marzal, «Del muro a la pantalla, y de la pantalla a la escritura », Hispanismes [En línea], 18 | 2021, Publicado el 31 diciembre 2021, consultado el 30 enero 2022. URL: http:// journals.openedition.org/hispanismes/14320 ; DOI: https://doi.org/10.4000/hispanismes.14320

Este documento fue generado automáticamente el 30 enero 2022

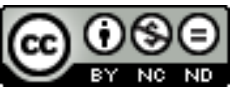

Les contenus de cette revue sont mis à disposition selon les termes de la Licence Creative Commons Attribution - Pas d'Utilisation Commerciale - Pas de Modification 4.0 International. 


\title{
Del muro a la pantalla, y de la pantalla a la escritura
}

\author{
De las fronteras entre ficción y autoficción en la obra de Almodóvar \\ Du mur à l'écran et de l'écran à l'écriture : les frontières entre fiction et \\ autofiction dans l'œuvre d'Almodóvar \\ From the wall to the screen, and from the screen to writing : the boundaries \\ between fiction and autofiction in Almodóvar's work
}

Belén Hernández Marzal

1 En Variations sur l'écriture, Roland Barthes pasa revista a todo lo referente al acto de escribir, tanto el acto en sí como los soportes dedicados a ello, recordándonos que «el muro llama a la escritura: en la ciudad no hay una pared sin graffiti» ${ }^{1}$, recordándonos, en fin, que todo muro puede convertirse -como ha venido haciéndose desde la Antigüedad- en soporte de escritura o de creación.

2 Y ese es el primer aspecto que analizaremos: centrándonos en la película Dolor y gloria de Pedro Almodóvar, veremos, pues, de qué manera el muro se torna en soporte de escritura, en este caso fílmica, para narrar, como comprobaremos a continuación, una obra en la que lo ficcional y lo autobiográfico parecen fisurar a partes iguales el muro, haciendo más porosas las fronteras entre ficción y vida².

\section{De la permeabilidad de los soportes}

Los muros como espacio de expresión son un elemento común de todo entorno urbano, como también en la filmografía de Almodóvar: muros como soporte de expresión, como lienzos en blanco en los que se da rienda suelta a cualquier forma de creatividad, en el caso del Street Art -citaremos tan solo a modo de ejemplo los grafitis que pueden apreciarse en los muros del barrio obrero en el que viven Raimunda y su hija en Volver-; muros como vehículo para la libertad de expresión, para cualquier tipo de protesta, como podemos ver en las pintadas que aparecen en algunos fotogramas de Dolor y gloria, como "yo sí te creo», pintada feminista referencia al caso "la Manada", cuando 
Salvador va a buscar droga en un barrio marginal, o por ejemplo, en otro momento de la película, cuando Federico pasea por el barrio Embajadores, la pintada «Lavapiés ingentrificable», a la que se le ha tachado el prefijo negativo «in-», referencia al fenómeno de la gentrificación que asola muchas de las grandes ciudades europeas, vaciando así a los barrios más humildes de la ciudad -en el caso de Dolor y gloria Lavapiés-, para llenarlos de habitantes más bohemios, de turistas, cambiando comercios tradicionales por barberías hípsters, cafeterías «instagrameables» o tiendas de cupcakes... O incluso en su última película, el mediometraje La voz humana, en la que el skyline urbano es sustituido por un muro desnudo, el del estudio cinematográfico, para traducir la extrema soledad en la que se encuentra el personaje encarnado por Tilda Swinton ${ }^{3}$.

El muro es, en definitiva, un lugar de expresión, tanto artística en el caso del Street Art, como en el universo de Almodóvar, para quien remite a una personal escena primigenia que relata en su discurso de Investidura como Doctor "Honoris Causa" por la Universidad de Castilla-La Mancha:

Ficción para mí era el mundo del patio, las vecinas, mis hermanas recibiendo clases de costura, con sus amigas, los gatos, las matanzas, los gitanos, los cantaores que venían en la feria, el twist, un conejo despellejado, todavía sangrante, bajo la parra; mi madre hablando con las vecinas en la puerta de la calle, al fresco de las largas noches de verano... y la gran pantalla de cine al aire libre. Un grueso muro, único fetiche al que me mantengo fiel. Detrás del muro pintado de blanco, los chicos hacíamos nuestras necesidades. Mito y fisiología. No lo sabía pero estaba aprendiendo lo esencial ${ }^{4}$.

5 Esta cita encierra la esencia, los pilares, por así decirlo, del cine según Almodóvar: la palabra -la de su madre, las de las vecinas-, sinónimo para el cineasta de ficción ${ }^{5}$, el muro, que mediante un desplazamiento metonímico se convierte en pantalla, metonimia asimismo del cine... En definitiva, el muro como lugar donde converge la ficción. De hecho, del muro a la pantalla solo hay un paso para el cineasta español.

6 Pantalla en blanco, página en blanco... Como las sábanas blancas que lavan en el río su madre y las mujeres y que dejan secar entre los juncos, que evocan para Salvador Mallo, el cineasta adulto protagonista de Dolor y gloria, «uno de los momentos más felices de su vida $»^{6}$. Y realmente pantalla y página no están tan alejadas la una de la otra, al menos en el cine de Almodóvar, donde de la página a la pantalla y de la pantalla a la página hay solo un paso, donde asistimos a menudo a ese trasvase entre ambas superficies, soportes, ambas, de la ficción. Es el caso, por ejemplo, de La mala educación ${ }^{7}$, en la que mediante el fundido encadenado pasamos de la página -el texto mecanografiado del relato «La visita»- a la historia narrada en ese mismo relato tal y como la imagina el director protagonista, Enrique Goded, alter ego de Almodóvar, y que resultará ser la historia que Enrique rodará de hecho a continuación...

7 Es el caso también en Dolor y Gloria, donde Alberto Crespo, actor del pasado de Salvador Mallo con el que se reencuentra tras treinta y dos años sin hablarse, visita al cineasta. Tras fumar un chino, Salvador se queda traspuesto y Alberto, aburrido, enciende el ordenador de Salvador y entre los diversos ficheros da con el relato «La adicción», cuyo título le llama mucho la atención y se dispone a leerlo. En esta secuencia, la página se superpone como en sobreimpresión, mediante un fundido encadenado, a lo que Alberto imagina será la puesta en escena, enlazando, como la secuencia antes mencionada de $L a$ mala educación, con un motivo esencial en el cine almodovariano que es el del cine en el cine. La mise en abyme se realiza, a menudo, siguiendo la misma dinámica: del texto 
escrito hacia la narración fílmica, de la página a la pantalla, introduciéndonos así en otra historia que se sitúa en otro nivel diegético ${ }^{8}$, produciéndose el efecto cine en el cine, puesto que la historia narrada se inserta en el marco de la película que estamos viendo, como si fueran muñecas rusas. Las primeras líneas del relato nos sumergen en los recuerdos de Salvador, como sugiere el movimiento del texto, de derecha a izquierda, como si nos retrotrajeran al pasado. La evocación de los muros encalados del cine de verano lleva a Alberto a imaginar una puesta en escena despojada de toda artificiosidad, tan solo una pantalla que remite a los muros encalados de la infancia de Salvador como único elemento escenográfico, como se puede corroborar en las acotaciones del guión:

Alberto se imagina a sí mismo en un escenario aséptico, con solo una gran pantalla al lado. En esta parte del monólogo, la pared real del escenario está pintada de negro, como todo el teatro. Sobresale alguna tubería, y un equipo, cuadrado, con una manguera antiincendios color rojo, todo protegido por un cristal.

ALBERTO: Las películas se proyectaban sobre un muro enorme, encalado de blanco.

(En su imaginación, Alberto se acerca a la pantalla blanca que representa el muro blanco en forma de rectángulo)'.

8 Tanto Alberto como Salvador imaginan la misma puesta en escena ${ }^{10}$, como se puede comprobar más adelante en la película cuando Salvador le da a Alberto -a quien le cede por fin los derechos de «La adicción»- algunos consejos de puesta en escena: «Sobre la puesta en escena te sugiero un escenario vacío. Una pantalla... una silla... si no sabes qué hacer con los brazos y las manos»"11.

Y puesto que el autor de las páginas, Salvador Mallo, se pone completamente al desnudo en este relato confesional, como él mismo lo define ante Alberto Crespo, también el actor se pone al desnudo ante la pantalla blanca, en un escenario prácticamente desnudo, con tan solo las marcas de cinta adhesiva en el suelo ${ }^{12}$, una silla, una pantalla en blanco y un radiocasete.

Dichos ejemplos dan cuenta de un elemento esencial en la filmografía de Almodóvar, a saber, la permeabilidad de los soportes de escritura, tanto fílmica como artística, recordándonos en Dolor y gloria, que la pintura y la escritura no están tan alejadas, como le dice el pequeño Salvador a Eduardo, puesto que «escribir es como dibujar, pero con letras» ${ }^{13}$-y la mano del pequeño Salvador enseñando a Eduardo el gesto de escribir traduce perfectamente las relaciones entre el gesto escritural y el cuerpo ${ }^{14}$; recordándonos asimismo que, además de los muros encalados, como páginas en blanco, o incluso como lienzos, cualquier superficie, por humilde que sea, puede ver surgir la belleza, como es el caso de Eduardo el albañil que pinta en un saco de cemento ${ }^{15}$ un hermoso dibujo de Salvador niño leyendo que se expondrá, cincuenta años después, en una galería de arte.

11 Del mismo modo que los muros en Almodóvar se muestran, en definitiva, porosos, o incluso reversibles, puesto que el muro es pantalla y página, y esta, a su vez, puede transformarse en pantalla, bien podría afirmarse que tampoco delimitan el espacio público del privado, ni la ficción de la realidad.

\section{De la permeabilidad entre ficción y realidad}

En Dolor y gloria, Almodóvar parece darle una vuelta más de tuerca al tema de la autoficción. Dice la sinopsis: 
Dolor y Gloria narra una serie de reencuentros, algunos físicos y otros recordados después de décadas, de un director de cine en su ocaso. Primeros amores, segundos amores, la madre, la mortalidad, algún actor con el que el director trabajó, los sesenta, los ochenta y la actualidad. Y el vacío, el inconmensurable vacío ante la imposibilidad de seguir rodando. También habla del teatro como elemento que dinamita/dinamiza el pasado y lo arrastra hasta el presente. Habla de la creación, cinematográfica y teatral, y de la imposibilidad de separar la creación de la propia vida $^{16}$.

El personaje principal, un director aquejado por el síndrome Bartleby, como el director protagonista de Otto e mezzo, es un autor atenazado por la depresión, en plena crisis existencial y creativa, que recobra la ilusión volviendo a los inicios, al punto de origen, que no es otro que la escritura, tanto fílmica como literaria, la página o el muro, ambos en blanco, promesas de creación.

Almodóvar se queda en la tenue frontera entre la ficción y la autoficción. Su personaje principal es una versión imaginada de sí mismo -retrato ficticio del autor- que, aunque no se llame como él -requisito, según Alberca de la autoficción- ${ }^{17}$, sí tiene mucho de sí mismo.

Si bien a Almodóvar no le molesta que cataloguen la película como autoficción, sí deja claro que no lo es... pero sin descartar la gran parte de sí mismo presente en la película:

No es que me moleste que la película se vea como una autoficción, y me parece halagador cuando dicen que hay un momento en el que Antonio Banderas, que encarna a Mallo, desaparece y me ven a mí. Me impresiona porque Antonio en ningún momento intentó imitarme, aunque tenga mi pelo, mi casa, mis colores... [...] Dolor y gloria no es autoficción, pero es cierto que la película parte de mí $\mathrm{mismo}^{18}$.

En cambio, en el capítulo «Almodóvar (autoficción)» de su obra dedicada al cineasta manchego, José Luis Sánchez Noriega, partiendo del presupuesto de que «la creación genuina es necesariamente personal» prefiere utilizar dicho término en lugar de «autobiografía» para designar el uso ficcional que hace el director de los episodios autobiográficos en su obra cinematográfica, pues le parece «más provechoso hablar de autoficción cuando nos referimos a relatos que no vienen avalados por la "verdad" de los datos comprobables de la vida del creador, ni tampoco se sitúan en el ámbito de la pura ficción sin anclaje alguno con la biografía» ${ }^{19}$.

Para añadir más confusión, el término «autoficción» es el que empleará Jacinta, madre en la pantalla de Salvador Mallo, en la conversación que mantiene con su hijo mostrando así su descontento ante el uso que hace su hijo de cualquier material autobiográfico en su filmografía. Aunque -todo hay que decirlo- el uso del término por su madre, Jacinta, le causa cierta gracia al hijo director, es, de hecho, la primera vez que aparece dicha denominación en una de las películas de Almodóvar. En la secuencia en cuestión, la madre le está contando a Salvador un sueño que tuvo con una vecina del pueblo ya fallecida, Petra. La madre le habla con la naturalidad de quien no ve muros ni fronteras entre vida y muerte, entre sueño y vida, entre ficción y realidad, quizás por lo vívidos que son algunos sueños, quizás también por hallarse cerca de la muerte ${ }^{20}$. Salvador quiere saber más y le pregunta a su madre «¿qué más?», a lo que la madre responde « ¡No pongas esa cara de narrador! ¿eh? ¡No, no, no! ¡no quiero que pongas nada de esto en tus películas. No me gusta que salgan mis vecinas, no me gusta la autoficción $»^{21}$. En este diálogo con la madre está la clave: la reelaboración de cualquier material que se halle a su alrededor para integrarlo a sus películas. De hecho, 
Almodóvar suele contar en entrevistas cómo se enfadaban algunas de las vecinas del pueblo cada vez que se las mencionaba en alguna de sus películas.

La película está puntuada de lo que parecen ser flashbacks de inspiración autobiográfica, pero ficcionalizados, hasta tal punto que podemos preguntarnos dónde se sitúa el límite, la frontera entre autobiografía y ficción. En ellos aparece una visión un tanto idealizada de su madre, que no tiene los rasgos de Julieta Serrano joven, sino los de una Penélope Cruz que se parece a Sophia Loren. Esta versión idealizada no es sino la versión reelaborada y fantaseada que Salvador, el autor protagonista, imagina como puesta en escena para su película, El primer deseo, tal como la llevará de hecho a la pantalla, como descubriremos en la secuencia final de la película ${ }^{22}$.

Efectivamente, el espectador descubre que los fragmentos autobiográficos que parecen funcionar como flashbacks, no lo son realmente, y que vienen a funcionar más bien como flashforwards ${ }^{23}$, puesto que se trata de los fragmentos que rodará Salvador Mallo después de atravesar su crisis personal y creativa. Una vez más se nos recuerda que todo lo que pueda parecer autobiográfico en el cine de Almodóvar es, al fin y al cabo, producto de la reelaboración de un determinado material pasado por el filtro de la ficción. En Dolor y gloria no nos muestra su infancia, sino una versión ficcionalizada de esta, su recuerdo idealizado, la versión transfigurada, como apunta Gustavo Martín Garzo, por la mirada encantada del niño, que el adulto debe recuperar para poder reconectar con su esencia:

En Dolor y gloria se reivindica el poder de la visión, que no es otra cosa que mirada encantada. La mirada del niño en el río viendo a su madre y a las otras mujeres tender la ropa en la hierba, la mirada del niño entre las paredes de esa cueva blanca que es el palacio secreto de la memoria, su mirada ante la pantalla blanca del cine en las noches de verano. Y será una mirada así la que Salvador Mallo tenga que recuperar, pues si ha dejado de hacer cine es simplemente porque ha dejado de ver $^{24}$.

\section{(Auto)ficción, autorreferencialidad}

En realidad, los elementos autobiográficos que aparecen diseminados en la película tampoco son tantos, y los que aparecen lo hacen transfigurados por un velo ficcional. De hecho -y aquí el muro se torna palimpsesto de películas anteriores ${ }^{25}-$, es un procedimiento habitual en la filmografía del director manchego, que para construir sus personajes ha ido dejando diseminados, de película en película, datos biográficos. Es el caso, por ejemplo, de Leo Macías en La flor de mi secreto cuando relata el origen de su vocación literaria, que se inicia con las cartas que escribía para los vecinos analfabetos, como hacía el mismo Almodóvar. Aquí es Eduardo, el guapo albañil al que el niño Salvador ayuda a alfabetizar, al que le enseña "a leer, escribir y las cuatro reglas», referencia a su infancia cuando les enseñaba a leer a los mozos del pueblo, a diferencia que no es Paterna, pueblo de la Comunidad Valenciana, sino un pueblo extremeño:

Yo tendría nueve años, vivíamos en Orellana la Vieja, en una zona semisalvaje y pizarrosa. Las casas improvisaban una calle donde sobresalían grandes bloques de pizarra. Era el barrio más barato del pueblo, por eso nos instalamos allí; a mis hermanas no les gusta recordar esa época, ellas ya se daban cuenta de las dificultades que atravesábamos. [...]

Nuestros vecinos eran gente muy cálida, pero analfabeta; mi madre decidió para ayudarles y ayudar nuestra pequeña economía (mientras mi padre trabajaba fuera), montar un pequeño negocio de alfabetización. A pesar de mis nueve años, a mí me 
nombró maestro... El proyecto se componía de dos partes. Por un lado, «lectura y escritura de cartas a domicilio»; y, por otra, en calidad de maestro yo les daba clase a los mozos que trabajan en el campo. Leer y escribir y las cuatro reglas. Según mi madre, aquellos hombretones vestidos de domingo le decían que yo era un profesor muy duro ${ }^{26}$.

Si bien en todas sus películas deposita «fragmentos de [sí] mismo o de la gente que [le] rodea» ${ }^{27}$, si bien el mismo Almodóvar no duda en calificar a su obra como autorreferencial ${ }^{28}$, la parte ficcional es bastante importante. Es más, el material autobiográfico, una vez trabajado, se convierte en ficción: «Es como cuando he escrito partiendo de hechos reales, en el momento en que empiezan a definirse como materia de ficción el origen desaparece. Quiero decir que bien avanzado el guión no tenía la sensación de estar escribiendo sobre mí. Y mucho menos cuando lo estaba rodando» ${ }^{29}$.

Por otra parte, aunque se base en los recuerdos de su infancia para construir algunas escenas de la película, parece ser que el director nunca conoció al personaje del albañil Eduardo de Dolor y gloria, aunque bien podría haber existido ${ }^{30}$. Tampoco ha tomado nunca heroína, a diferencia de su alter ego en la película, que encuentra en la droga un alivio a sus dolores físicos (operación de la espalda) y anímicos (la depresión en la que se halla sumido tras la muerte de su madre y su incapacidad a trabajar en algo tan físico como el cine). Es como si Almodóvar explotara las diferentes potencialidades que se le podrían haber presentado en la vida, una de tantas posibilidades de lo que bien hubiera podido ser:

Dolor y gloria es más bien un retrato ficticio de Salvador Mallo, un escritor y director de cine ya mayor -interpretado por Antonio Banderas- que sufre de depresión, aislamiento social, es drogadicto y teme no volver a poder hacer una película. «Es más Almodóvar que Almodóvar», señala el actor malagueño, «haciendo esta película es la manera que tiene para completar áreas de ese puzle de su vida» ${ }^{31}$.

Cuanta más ficción, más cerca de la esencia parece encontrarse, pues como apunta Guilherme de Alencar Pinto, «la versión ficcionalizada puede ser la elaboración ideal de verdades más verdaderas que lo factual ${ }^{32}$. De hecho, son los dos momentos de la película que no pertenecen a su biografía, a los que califica como «momentos de pura ficción», los que, según el director, mejor lo representan y más emoción suscitaron en él ${ }^{33}$. Y añade: «No es nada nuevo, la ficción es el mejor modo de indagar acerca de la realidad, incluida la realidad propia» ${ }^{34}$.

Acaso vuelva una y otra vez, película tras película, a la enseñanza primordial que le dejó su madre, a saber, la absoluta necesidad de la ficción, tanto en la vida como en cualquier tipo de creación: «no se trataba de ser complaciente, sino de perfeccionar la realidad, añadiéndole un poco de ficción. Eso es lo que yo he hecho con los guiones de mis películas. Les he añadido algo más que un poco de ficción» ${ }^{35}$.

Entonces, ¿Este (no) soy yo!, como diría Alberca? En el terreno de la autoficción, como apunta el especialista, «la contradicción se vuelve, además de verosímil, natural, pues como contestó la escritora francesa Annie Ernaux a la pregunta de quién hablaba en su libro Passion simple: "C'est moi et ce n'est pas moi"»"

En su prólogo al guión, el director juega con esta ambigüedad:

¿Es Dolor y gloria una película basada en mi vida? No, y sí, absolutamente. Todas mis películas me representan. Es cierto que esta me representa más, pero desde el momento en que empiezo a escribir sobre una base conocida -procedente de la realidad, de algo que he leído en el periódico, que me han contado, de lo que he sido testigo o simplemente un episodio de mi propia vivencia- la historia empieza a 
encontrar su verdadero camino (cinematográfico, en este caso) para convertirse en ficción. El resto del trabajo lo hago guiado e impulsado por la imaginación. Y la imaginación no se preocupa tanto de la verdad como de la verosimilitud, y de que el resultado sea entretenido y emocionante ${ }^{37}$.

No, sí, absolutamente... quizás... Es en esa frontera, en esa zona de indefinición en la que permanece Almodóvar, en la zona en la que los diferentes estratos se superponen, a manera de palimpsestos, en el muro... recordándonos la fórmula de los cuentistas mallorquines «Això era i no era» que tanto les llamó la atención a Jakobson y a Genette $^{38}$, recordándonos, con Borges y Rimbaud, que «Yo es otro».

Pedro Almodóvar le presta a Salvador Mallo su ropa, sus zapatos e incluso su peinado. Es tal el trabajo de actor de Antonio Banderas que por momentos parecería que estuviéramos escuchando al mismísimo Almodóvar, con el que parece mimetizarse hasta el punto de captar las más mínimas inflexiones de voz. La casa en la que vive Salvador es una réplica exacta del piso de Pedro Almodóvar, quien prestó sus cuadros ${ }^{39}$ para reproducir su propia casa en el set de rodaje.

¿Cómo no pensar en la prosa de Jean Tardieu, «Abus de confiance»? parece resumir a la perfección la manera de proceder de Almodóvar en esta película:

J'habite ici une maison en tous points semblable à la mienne : disposition des pièces, odeur du vestibule, meubles, lumière oblique le matin, atténuée à midi, sournoise le soir - tout est pareil, même les allées et les arbres du jardin et cette ancienne porte à demi démolie et les pavés de la cour. [...]

31 Mais, que l'on n'aille pas prétendre que c'est moi! Allons donc! Tout est faux, ici. Quand on m'aura rendu ma maison et ma vie - alors je retrouverai mon vrai visage ${ }^{40}$.

\section{Conclusión}

Quizás la visión almodovariana de la autoficción repose básicamente en la lección que aprendió con su madre. En el universo infantil del autor, las historias que contaban las vecinas ${ }^{41}$ se le antojan al niño «novelero» fascinantes ficciones, a la vez que aprendería de su madre la diferencia entre ficción y realidad ${ }^{42}$. Así, sirviéndose de elementos autobiográficos, más que rememorar, recrea, re-crea, haciendo hincapié en la parte ficcional, en la dosis de ficción necesaria, aunque pueda parecer paradójico, para hacer la historia más verosímil.

Son los muros encalados de blanco los que permiten una vuelta introspectiva al pasado, los que nos llevan a las noches de verano perfumadas de jazmín de la infancia de Almodóvar. El muro, simple pared blanca, cobra vida con las imágenes animadas del cinematógrafo y mediante un desplazamiento metonímico, se convierte en pantalla.

La evocación del muro como página en blanco o como pantalla en blanco donde se proyectaban las películas de su infancia le permite al autor la vuelta a una introspección donde lo más importante no es lo autobiográfico ni lo autorreferencial, sino la elaboración ficcional de dicho material. Es como si la ficción se colara entre las fisuras del muro, resquebrajándolo, dando como resultado una obra muy personal en la que la parte autobiográfica solo tiene sentido como generadora de ficción.

Dolor y gloria es una suerte de homenaje a los muros encalados, a la pantalla en blanco, al cine... a la vida, en definitiva, puesto que, para Almodóvar, cine y vida, ficción y 
realidad son indisociables. Y concluiremos con sus propias palabras: «Podría decir que el cine es mi vida o que mi vida es el cine» ${ }^{43}$.

\section{BIBLIOGRAFÍA}

Laure ADLER, «Pedro Almodóvar, une voix humaine» [podcast], L'Heure bleue, France Inter, 17/03/21 [consultado el 17/03/2021] <URL: https://www.franceinter.fr/emissions/l-heure-bleue/ 1-heure-bleue-17-mars-2021>.

Pedro ALMODÓVAR, Investidura como Doctor «Honoris Causa» por la Universidad de Castilla-La Mancha del Exmo. Sr. D. Pedro Almodóvar Caballero, Ciudad Real, Universidad de Castilla-La Mancha, 2000.

Pedro ALmodóvaR, Dolor y gloria, Guión [Formato Kindle], Barcelona, Penguin Random House Grupo Editorial España, 2019.

Pedro ALMODóVAR, Dolor y gloria, (Douleur et gloire), [DVD], París, Pathé Films, 2019.

Pedro ALMODóVAR, Dolor y gloria, dossier de prensa, <https://www.espace-1789.com/sites/default/ files/film_files/douleur_gloire_dp_def.PDF>

Pedro ALMODÓVAR, Tráiler en francés de Dolor y gloria <https://www.youtube.com/watch? $\mathrm{v}=\mathrm{ixCIP0CCR5k}>$ [disponible el 31/07/2021].

Pedro ALMODóVAR, «El último sueño», El País (14/09/1999) [fecha de consulta 17/03/2021] <URL: http://elpais.com/diario/1999/09/14/opinion/937260006_850215.html>.

Pedro ALMODóVAR, La ley del deseo (1986), (La loi du désir), [DVD], El Deseo S.A., Paris, TF1 Vidéo, 2005.

Pedro ALMODóvAR, La mala educación, (La mauvaise éducation), (2004), [DVD], El Deseo S.A., Paris, Pathé distribution, 2006.

Pedro ALMODóVAR, La flor de mi secreto (1995), (La Fleur de mon secret), [DVD], El Deseo S.A., Paris, TF1 Vidéo, 2005

Pedro ALMODóVAR, Todo sobre mi madre (1999), (Tout sur ma mère), Paris, [DVD], El Deseo S.A., Pathé distribution, 2006.

Manuel ALBERCA, El pacto ambiguo: de la novela autobiográfica a la autoficción [formato Kindle], Madrid, ed. Biblioteca Nueva, 2013.

Manuel ALBERCA, «jÉste (no) soy yo? Identidad y autoficción», Pasajes, Revista de pensamiento contemporáneo, 2008, $\mathrm{n}^{\circ} 25$, p. 89-102.

Daniela ARONICA, «Intertextualidad y autorreferencialidad: Almodóvar y el cine español», en Fran A. ZURIÁN, Carmen VÁZQUEZ VARELA (coordinadores), Almodóvar: el cine como pasión, Actas del Congreso Internacional "Pedro Almodóvar", Cuenca, Ediciones de la Universidad Castilla-La Mancha, 2005, p. $57-80$.

Roland BARTHES, Variations sur l'écriture, dans Le plaisir du texte, précédé de Variations sur l'écriture, Paris, Ed. Seuil, 2000. 
Roland BARTHES, Variaciones sobre la escritura, Barcelona, Ed. Paidós Ibérica, 2002.

Julio CORTÁZAR, Rayuela, Madrid, Cátedra, 1998.

Guilherme DE ALENCAR PINTO, «Reencuentros y despedidas: Dolor y gloria, de Pedro Almodóvar», 7/6/2019, [disponible el 29/07/21] <URL: https://ladiaria.com.uy/cultura/articulo/2019/6/ reencuentros-y-despedidas-dolor-y-gloria-de-pedro-almodovar/>.

Paul DUNCAN (ed.), Bárbara PEIRó (col.), Los archivos de Pedro Almodóvar, Taschen, 2017.

EL DESEO (página oficial), [disponible el 29/07/21] <URL: https://www.eldeseo.es/dolor-y-gloria/>. ELDESEOPC (cadena YouTube) [disponible el 1/9/2021] <URL: https://www.youtube.com/watch? $\mathrm{v}=$ WsH1LVlETH0>.

Gérard GENETTE, Fiction et diction, Paris, Seuil, 1991.

Martín MUCHA, «El niño del cuadro (de Dolor y Gloria) que sí es Almodóvar», El mundo, 25/09/2019, <https://www.elmundo.es/cronica/2019/09/25/5d8a05cbfc6c838e428b45a1.html> [disponible el 29/07/21].

Sandro POZZI, «La autoficción de Almodóvar debuta en Nueva York», El País, 27/09/2019, <https:// elpais.com/cultura/2019/09/27/actualidad/1569596158_747654.html> [disponible el 31/07/2021].

José Luis SÁNCHEZ NORIEGA, Universo Almodóvar. Estética de la pasión en un cineasta posmoderno, Madrid, Alianza Editorial, 2017.

TABACALERA. PROMOCIÓN DEL ARTE (2021), «Flores. Pedro Almodóvar y Jorge Galindo» [consultado el 24/03/2021] <URL: https://www.promociondelarte.com/tabacalera/expo-454-flores-pedroalmodovar-y-jorge-galindo>.

Jean TARDIEU, La part de l'ombre, suivi de Première personne du singulier, Paris, Gallimard, 1972.

\section{NOTAS}

1. «Le mur, on le sait, appelle l'écriture : pas un mur, dans la ville, sans graffiti. C'est en quelque sorte le support lui-même qui détient une énergie d'écriture, c'est lui qui écrit et cette écriture me regarde : rien n'est plus voyeur qu'un mur écrit parce que rien n'est regardé, lu, avec plus d'intensité [...]». Roland Barthes, Variations sur l'écriture, dans Le plaisir du texte, précédé de Variations sur l'écriture, Paris, Ed. Seuil, 2000, p. 74. La traducción es la de la edición española del libro: Roland Barthes, Variaciones sobre la escritura, Barcelona, Ed. Paidós Ibérica, 2002, p. 131.

2. Este es el resumen que aparece en el guión de la película: «Salvador Mallo es un veterano director de cine aquejado de múltiples dolencias, pero el peor de sus males es la incapacidad para seguir rodando. La mezcla de medicamentos y drogas hace que Salvador pase la mayor parte del día postrado. Este estado de duermevela le traslada a una época de su vida que nunca visitó como narrador: su infancia en los años sesenta, cuando emigró con sus padres a un pueblo de Valencia en busca de prosperidad. También se le vuelve a aparecer su primer amor adulto, ya en el Madrid de los ochenta, y el dolor que supuso la ruptura. Salvador se refugia en la escritura como única terapia para olvidar lo inolvidable. Ese ejercicio lo devuelve al temprano descubrimiento del cine, cuando las películas se proyectaban sobre un muro encalado, al aire libre, con olor a pis, a jazmín y a brisa de verano. De nuevo, descubrirá que el cine puede ser su única salvación frente al dolor, la ausencia y el vacío». Pedro ALMoDóvAR, Dolor y gloria, Guión [Formato Kindle], Barcelona, Penguin Random House Grupo Editorial España, 2019, posición 2681. 
3. Muro que, según palabras de Almodóvar, «aumenta la sensación de soledad, la oscuridad, casi de absurdo, en el que vive la protagonista», Laure ADLER, «Pedro Almodóvar, une voix humaine» [podcast], L'Heure bleue, France Inter, 17/03/21 [consultado el 17/03/2021] <URL: https:// www.franceinter.fr/emissions/l-heure-bleue/l-heure-bleue-17-mars-2021>.

4. Investidura como Doctor "Honoris Causa" por la Universidad de Castilla-La Mancha del Exmo. Sr. D. Pedro Almodóvar Caballero, Ciudad Real, Universidad de Castilla-La Mancha, 2000, p. 18.

5. Se trata de un motivo recurrente, tanto en sus películas (La flor de mi secreto, Volver...), como en sus escritos o entrevistas.

6. «A los tres años Salvador no es consciente de que este será uno de los momentos más felices de su vida. Todo es perfecto, el agua del río, los peces en las manos, las sábanas blanquísimas sobre juncos y poleo, su madre sonriente, y las mujeres cantando "A tu vera"». Pedro ALMODóVAR, Dolor y gloria, Guión, op. cit., posición 149.

7. En La mala educación, Enrique Goded, director de cine en plena crisis de inspiración y alter ego de Pedro Almodóvar, recibe la visita del que se presenta como su antiguo amigo de infancia (y antiguo amor), Ignacio, que se hace llamar ahora Ángel Andrade, con un relato titulado «La visita» que habla de su infancia en el colegio religioso donde estudiaron.

8. Los fragmentos correspondientes a las películas que rodarán Eduardo Goded y Salvador Mallo aparecen insertados en el marco de la película y corresponden, pues, a otro nivel diegético. En el caso de La mala educación, como ya hemos mencionado, Ignacio / Ángel visita a Eduardo Goded para proponerle el relato «La visita», cuyo personaje principal, Zahara, vuelve a su antiguo colegio de curas, donde visita a su profesor de literatura, el padre Manolo, para chantajearlo amenazándolo con la publicación del relato titulado «La visita». A su vez, Enrique Goded llevará el relato a la gran pantalla, titulando la película, obviamente, La visita.

9. Pedro ALMODóvAR, Dolor y gloria, Guión, Secuencia 39, op. cit., posición 668.

10. A no ser que se trate de un flashforward que anuncie la secuencia de la representación de Alberto que juega un papel esencial en la película.

11. 00:55:17 en la película, posición 1268 en el guión, op. cit.

12. Escenario minimalista a la manera de Dogville de Lars Von Trier, donde las marcas en el suelo con cinta adhesiva representaban los contornos de las casas.

13. «En Orient, on le sait, c'est (ou du moins ce fut) tout autre chose. L'écriture a été dès son origine liée au dessin (ceci est conforme à la physiogenèse, à ce qu'on peut savoir des tracés préhistoriques, et à l'ontogenèse puisque déjà, au dire de Pestalozzi, l'enfant est apte à dessiner deux ans avant d'écrire): c'est un même geste que celui de l'artiste et celui du scripteur. L'écriture orientale est donc logiquement calligraphique; c'était un art noble (aux côtés du tir à l'arc, de la musique, de la science divinatoire des nombres, de la conduite, des chars), voire magique, impliquant une maîtrise psychosomatique; en Occident, il s'agissait de dompter le corps (et par suite de l'émanciper); en Orient, de la maîtriser (et par suite d'affiner sa jouissance). Le développement de l'écriture orientale, c'est donc la peinture dans son immensité», Roland BARTHES, Variations sur l'écriture, dans Le plaisir du texte, op. cit., p. 65. En el capítulo titulado «Origen», Barthes habla también de «los lazos originales entre la escritura y el arte figurativo o abstracto. Variaciones sobre la escritura, op. cit., p. 40-41.

14. Roland BARTHES, «La relation à l'écriture c'est la relation au corps», Variations sur l'écriture, dans Le plaisir du texte, op. cit., p. 64.

15. El dibujo de Salvador leyendo es obra del pintor madrileño Jorge Galindo, al que el director admira y con el que colaboró en el proyecto Flores. Esta es la presentación de la exposición que aparece en la página web de la sala Tabacalera La Principal y que tuvo lugar entre el 22-11-2019 y el 26-01-2020: «Tomando como partida las fotografías de bodegones realizadas por el cineasta, ambos han trabajado mano a mano en la creación de grandes obras pictóricas, siendo sus herramientas la acción y el gesto espontáneo con los elementos pictóricos. La reflexión sobre la flor, como elemento básico y recurrente en toda la historia del arte, es la perfecta excusa para el 
desarrollo de estas obras dirigidas, que reivindican lo propiamente sensorial a través de la contemplación.

La exposición la componen casi medio centenar de obras, la mayoría de gran formato, destacando un gran cuadro, sin título, que abre la exposición y que tiene un formato de seis metros de alto por once de largo». TABACALERA. PROMOción DEL ARTE (2021), «Flores. Pedro Almodóvar y Jorge Galindo» [consultado el 24/03/2021] <URL: https://www.promociondelarte.com/tabacalera/ expo-454-flores-pedro-almodovar-y-jorge-galindo>.

$\mathrm{Y}$ este es el vídeo que muestra el trabajo a cuatro manos de Jorge Galindo y Pedro Almodóvar: <URL: https://www.youtube.com/watch?v=WsH1LVlETH0> [consultado el 24/3/2021]. Las pinturas y obras de arte que se ven en casa de Salvador Mallo forman parte de la colección personal de Almodóvar, a excepción de la de la pintora Maruja Mallo. Al cineasta siempre le ha gustado vivir rodeado de obras de arte, de hecho, al ver la casa Federico Delgado le dice a Salvador «Parece un museo».

16. EL DESEO (página oficial), [disponible el 29/07/21] <URL: https://www.eldeseo.es/dolor-ygloria/>.

17. Según Alberca «una autoficción es una novela o relato que se presenta como ficticio, cuyo narrador y protagonista tienen el mismo nombre que el autor», Manuel ALBERCA, El pacto ambiguo: de la novela autobiográfica a la autoficción [formato Kindle], Madrid, ed. Biblioteca Nueva, 2013, posición 1859-1860. En su artículo «iÉste (no) soy yo? Identidad y autoficción» añade: «Una autoficción es una novela, que, igual que todas las novelas, deja libres al autor y al lector para imaginar como verosímil la historia inventada que allí se cuenta, pero en la que pareciera que el novelista se comprometiese a decir la verdad sobre su vida y sobre sí mismo, al atribuir a su protagonista y narrador un nombre propio idéntico al suyo, como sucede en las obras que se someten al pacto autobiográfico. Esta estructura híbrida y el pacto de lectura ambiguo consiguiente la convierten en una metáfora de la actual deriva del sujeto y de la fuerte mutación que éste experimentó en el siglo pasado. En este contexto, la identidad del autor no debemos entenderla como sustancia o esencia, sino como su representación o figura, aprensible directamente en el texto narrativo, en la cual se percibe la correspondencia referencial entre el plano del enunciado y de la enunciación, entre el protagonista y su autor, como resultado siempre de una transfiguración literaria» Manuel ALBERCA, «jÉste (no) soy yo? Identidad y autoficción», Pasajes, Revista de pensamiento contemporáneo, 2008, nº 25, p. 89.

La diferencia con Dolor y gloria es que, si bien Almodóvar cuenta una historia «verosímil», o que al espectador puede parecerle verosímil, el personaje principal no se llama como él.

18. Pedro AlmodóVAR, Dolor y gloria, Guión, op. cit., posición 35-43.

19. José Luis SÁNCHEZ NORIEGA, Universo Almodóvar. Estética de la pasión en un cineasta posmoderno, Madrid, Alianza Editorial, 2017, p. 30.

20. La cultura y supersticiones de La Mancha en torno a la muerte están muy presentes en Volver. En el guión de Dolor y gloria, la define como «una película que habla de la cultura de la muerte en mi tierra, el culto a los muertos, algo que de niño me daba mucho miedo, fui tomando conciencia de que me sentía muy reconfortado con aquella «primera educación» que recibí de mi madre y sus vecinas». Pedro ALMODÓVAR, Dolor y gloria, Guión, op. cit., posición 2331-2339.

21. Pedro ALMODÓvar, Dolor y gloria, Guión, op. cit., posición 1942.

22. Como en La mala educación, las secuencias de la película en la película aparecen imaginadas primero por el director, Enrique Goded en La mala educación, que imagina cómo llevará a la pantalla «La visita», y Alberto Crespo, que imagina la puesta en escena de «La adicción».

23. «A la madre la veremos por primera vez al borde del agua, lavando ropa, en uno de esos flashbacks que, como veremos, son flashforwards». Guilherme DE ALENCAR PINTO, «Reencuentros y despedidas: Dolor y gloria, de Pedro Almodóvar», 7/6/2019, [disponible el 29/07/21] <URL: https:// 
ladiaria.com.uy/cultura/articulo/2019/6/reencuentros-y-despedidas-dolor-y-gloria-de-pedroalmodovar/>.

24. Epílogo de Gustavo Martín Garzo al guión de Dolor y gloria, Pedro ALMODóvar, Dolor y gloria, Guión, op. cit., posición 2666-2671.

25. Cabe destacar el carácter autorreferencial de la obra cinematográfica almodovariana, en la que cada película remite a las anteriores, en las que un personaje secundario puede convertirse en personaje principal de una película posterior, como el caso de Manuela en Todo sobre mi madre, que no es sino el desarrollo del personaje secundario de Manuela, enfermera de La flor de mi secreto. Dicho personaje, que interpreta Kiti Mánver, protagoniza una dramatización en el marco de un seminario destinado a preparar al personal sanitario a situaciones que se pueden presentar en su día a día, como es el caso de la donación de órganos, como Manuela (Cecilia Roth) en Todo sobre mi madre. También La mala educación retoma elementos de La ley del deseo, como la transexualidad y la educación religiosa. Con Dolor y gloria cierra una trilogía iniciada casi de manera inconsciente con La ley del deseo: «Sin haberlo pretendido Dolor y gloria es la tercera parte de una trilogía de creación espontánea que ha tardado treinta y dos años en completarse. Las dos primeras partes son La ley del deseo y La mala educación. Las tres películas están protagonizadas por personajes masculinos que son directores de cine, y en las tres el deseo y la ficción cinematográfica son los pilares de la narración, pero la forma en que la ficción se entrevera con la realidad difiere en cada una de ellas. Ficción y vida son las dos caras de la misma moneda, y la vida siempre incluye dolor y deseo». Pedro Almodóvar, Dolor y gloria, Guión, op. cit., posición 2309-2315.

26. Pedro ALMODóVAR, Investidura como Doctor «Honoris Causa» por la Universidad de Castilla-La Mancha), ibíd., p. 19.

27. «[...] hay mucho de mi biografía solapado detrás de personajes que en apariencia no tienen ningún parecido conmigo. En todas mis películas deposito fragmentos de mí mismo o de la gente que me rodea», Pedro ALMODóvAR, Dolor y gloria, Guión, op. cit., posición 2362.

28. El director manchego suele emplear los términos «autorreferencia»o "autorreferencialidad», que quizás correspondan mejor que el de «autoficción», para referirse a la presencia de sí mismo en su filmografía. Es este, además, el término que emplea en el dossier de prensa de la película. Dossier de prensa de Dolor y gloria, [consultado el 21/4/2021] <URL: https:// www.espace-1789.com/sites/default/files/film_files/douleur_gloire_dp_def.PDF >.

De hecho, el término «autorreferencialidad» es el que suelen emplear tanto la crítica como los estudiosos de la obra almodovariana para destacar la fuerte carga autorreferencial en el sentido autobiográfico del término. Así pues, Daniela Aronica insiste en el componente autorreferencial de la filmografía del director como forma de desvelarse sin mostrarse totalmente al desnudo: «La autorreferencialidad se convierte así en una herramienta para insinuarse hasta en los más recónditos pliegues de su universo existencial sin tenerse que desnudar ante el espectador de forma explícita. La apuesta por la sinceridad a toda costa, fundamento ético de la poética almodovariana, halla en la fragmentación discursiva posmoderna un espacio donde manifestarse con libertad. La misma libertad que tiene el espectador de reconstruir a su autor ideal a partir de las pistas que el autor real le proporciona [...].

La creación artística se convierte así en puente entre la esfera pública y la privada, en el escaparate desde donde Almodóvar se representa decidiendo hasta qué punto y de qué forma asomarse». Daniela ARONICA, «Intertextualidad y autorreferencialidad: Almodóvar y el cine español», en Fran A. ZURIÁN, Carmen VÁZQUEZ VARELA (coordinadores), Almodóvar: el cine como pasión, Actas del Congreso Internacional "Pedro Almodóvar", Cuenca, Ediciones de la Universidad Castilla-La Mancha, 2005, p. 78.

29. Pedro ALMODóvAR, Dolor y gloria, Guión, op. cit., posición 2360-2367.

30. A la pregunta de si existió o no Eduardo el albañil, el cineasta responde: «"No". Lo ha reiterado una y otra vez el cineasta manchego. "No, no me enamoré de ningún albañil... Aunque 
reconozco que podría haber ocurrido perfectamente". Lo usó como polea para dar sentido a su obra más biográfica». Martín MUCHA, «El niño del cuadro (de Dolor y Gloria) que sí es Almodóvar», El mundo, 25/09/2019, <URL: https://www.elmundo.es/cronica/ 2019/09/25/5d8a05cbfc6c838e428b45a1.html> [consultado el 20/04/2021]. Y aclara en el guión: «Me identifico con todas esas épocas, conozco los lugares y los sentimientos por los que atraviesa el personaje, pero nunca he vivido en una cueva ni me he enamorado de un albañil cuando era niño, por ejemplo, aunque ambas cosas podrían haber ocurrido, ni he tomado heroína». Pedro ALMODóvAR, Dolor y gloria, Guión, op. cit., posición 2378-2387.

Coincide en ello, en parte, con la definición de autoficción de Manuel Alberca citada anteriormente: la historia inventada que se cuenta en la película puede resultarle verosímil tanto al autor como al lector.

31. Sandro PozzI, «La autoficción de Almodóvar debuta en Nueva York», El País, 27/09/2019, <https://elpais.com/cultura/2019/09/27/actualidad/1569596158_747654.html> [consultado el 20/04/2021].

32. Guilherme DE ALENCAR PINTO, «Reencuentros y despedidas: Dolor y gloria, de Pedro Almodóvar», op. cit.

33. «Esta secuencia nunca ocurrió realmente y sin embargo creo que representa, mejor que nada de lo que he hecho hasta ahora, la sensación de extrañeza que yo veía en los demás durante las distintas etapas de mi infancia». Pedro ALMODóvar, Dolor y gloria, guión, op. cit., posición 2370.

34. Pedro ALMODóVAR, Ibid., 2378.

35. Pedro AlmodóvaR, Investidura como Doctor «Honoris Causa» por la Universidad de Castilla-La Mancha), ibíd., p. 20. Y, podríamos añadir, cuanta más ficción introduce, más fiel es a su verdadera esencia, un poco a la manera de Agrado en Todo sobre mi madre cuando dice «Porque una es más auténtica cuanto más se parece a lo que ha soñado de sí misma».

36. Manuel ALBERCA, El pacto ambiguo: de la novela autobiográfica a la autoficción, op.cit., posición 2488.

37. Prólogo de ALMODóVAR al guión de Dolor y gloria, op. cit., posición 21. El tráiler en francés de la película retoma las dos primeras frases. Cf. <https://www.youtube.com/watch?v=ixCIp0CcR5k> [consultado el 25/04/2021].

38. Gérard GENETTE, Fiction et diction, Paris, Seuil, 1991, p. 89.

39. Todos los cuadros que aparecen pertenecen a su colección personal menos uno, «El racimo de uvas», de la pintora surrealista Maruja Mallo, quien le presta su apellido a Salvador, el protagonista.

40. Jean TARDIEU, «Abus de confiance», en La part de l'ombre, suivi de Première personne du singulier, Paris, Ed. Gallimard, 1972, p. 166. Julio Cortázar traduce el texto de Tardieu cambiándole el título («Abuso de conciencia») y lo incluye en Rayuela: «Esta casa en que vivo se asemeja en todo a la mía; disposición de las habitaciones, olor del vestíbulo, muebles, luz oblicua por la mañana, atenuada a mediodía, solapada por la tarde; todo es igual, incluso los senderos y los árboles del jardín, y esa vieja puerta semiderruida y los adoquines del patio. [..]

¡Pero no se vaya a pretender que soy yo! ¡Vamos! Todo es falso aquí. Cuando me hayan devuelto mi casa y mi vida, entonces encontraré mi verdadero rostro». Julio CORTÁzAR, Rayuela, Madrid, Cátedra, 1998, p. 732.

41. Se trata de un motivo recurrente, tanto en sus películas (La flor de mi secreto, Volver...), como en sus escritos o entrevistas.

42. «Yo aprendí mucho de mi madre, sin que ni ella ni yo nos diéramos cuenta. Aprendí algo esencial para mi trabajo, la diferencia entre ficción y realidad, y cómo la realidad necesita ser completada por la ficción para hacer la vida más fácil. [...]

Como complemento al salario de mi padre, mi madre empezó con el negocio de la lectura y escritura de cartas, como en Estación Central de Brasil. Yo tenía ocho años; normalmente era yo 
quien escribía las cartas y ella quien leía las que nuestros vecinos recibían. En más de una ocasión yo me fijaba en el texto que mi madre leía y descubría con estupor que no correspondía exactamente con lo escrito en el papel: mi madre inventaba parte. Las vecinas no lo sabían, porque lo inventado siempre era una prolongación de sus vidas, y quedaban encantadas después de la lectura.

Después de comprobar que mi madre nunca se atenía al texto original, un día se lo reproché de camino a casa: “¿Por qué le has leído que se acuerda tanto de la abuela, y que echa de menos cuando la peinaba en la puerta de la calle, con la palangana llena de agua? La carta ni siquiera nombra a la abuela”, le dije yo. “Pero has visto lo contenta que se ha puesto!”, me dijo ella.

Tenía razón. Mi madre llenaba los huecos de las cartas, les leía a las vecinas lo que ellas querían oír, a veces cosas que probablemente el autor había olvidado y que firmaría gustoso.

Estas improvisaciones entrañaban una gran lección para mí. Establecían la diferencia entre ficción y realidad, y cómo la realidad necesita de la ficción para ser completa, más agradable, más vivible (Almodóvar, 1999)».

Pedro almodóvar CABAllero, «El último sueño», El País (14/09/1999) [fecha de consulta 17/03/2021] <URL: http://elpais.com/diario/1999/09/14/opinion/937260006_850215.html>. El texto aparece publicado asimismo en Los archivos de Pedro Almodóvar, edición de Paul Duncan, en colaboración con Bárbara Peiró, Taschen, 2017, p. 264.

43. Pedro ALMODóVAR, Dolor y gloria, guión, op. cit., posición 56.

\section{RESÚMENES}

La ficción para Almodóvar se resume al « patio, las vecinas [...] y la gran pantalla de cine al aire libre". Si en el principio era el Verbo, y más concretamente las conversaciones de su madre con sus vecinas, la gran pantalla de cine, el lugar donde se transpone la ficción, nunca está lejos de los inicios de la creación para el director español. Así, en Dolor y Gloria, las paredes encaladas parecen páginas en blanco, o incluso lienzos, porque la pintura y la escritura no están tan alejadas. Del mismo modo, las paredes encaladas de la casa-cueva de Paterna, donde Salvador vive con su familia, son el lugar donde surge no solo la escritura, sino también el deseo, el motor que impulsa tanto su vida como su obra (y por tanto la del propio Almodóvar). En este artículo, analizaremos en primer lugar los vínculos entre el muro encalado y la escritura y la forma en que Almodóvar utiliza estas imágenes para crear una obra autoficcional en la frontera entre la autobiografía y la ficción.

La fiction pour Almodóvar peut se résumer à « la cour, les voisines [...] et le grand écran de cinéma en plein air». Si au commencement était le verbe, et plus précisément les conversations de sa mère avec ses voisines, le grand écran de cinéma, lieu de transposition de la fiction, n'est jamais loin des prémices de la création pour le réalisateur espagnol. Ainsi, dans Douleur et gloire, les murs blanchis à la chaux ressemblent à des pages blanches, voire à des toiles, car la peinture et l'écriture ne sont pas si éloignées que cela. De même, les murs blanchis à la chaux de la maison troglodyte de Paterna, où Salvador vit avec sa famille, sont le lieu où émerge non seulement l'écriture, mais aussi le désir, le moteur qui anime à la fois sa vie et son œuvre (et donc celle d'Almodóvar lui-même). Dans cet article, nous analyserons d'abord les liens entre le mur blanchi à la chaux et l'écriture et la manière dont Almodóvar utilise ces images pour créer une œuvre autofictionnelle à la frontière entre autobiographie et fiction. 
Fiction for Almodóvar can be summed up in «the world of the courtyard, the neighbours [...] and the big open-air cinema screen». If in the beginning it was the verb, and more specifically his mother's conversations with the neighbours, the big cinema screen, the place of fiction's transposition, is never far from the beginnings of creation for the Spanish director. Thus, in Pain and Glory, the whitewashed walls are seen as blank pages, or even canvases, because painting and writing are not so far apart. In the same way, the whitewashed walls of the cave in Paterna where Salvador, the main character, lives with his family, are the place where not only writing emerges, but also desire, the driving force behind both, his life and his work (and therefore Almodóvar's himself).In this paper we will first analyse the connections between the whitewashed wall and the writing and the way Almodóvar uses these images and reworks autobiographical material in order to create an auto-fictional work on the borderline between autobiography and fiction.

\section{ÍNDICE}

Mots-clés: Pedro Almodóvar, autofiction, autoréférentialité

Keywords: Almodóvar, autofiction, autoreferentiality

\section{AUTOR}

\section{BELÉN HERNÁNDEZ MARZAL}

Université Jean Moulin Lyon 3 - MARGE 